\title{
(CON)TATTO. Image and Mental Imagery in Childhood Visual Impairment
}

\author{
Massimiliano Lo Turco ${ }^{1, *}$, Elisa Reinaudo ${ }^{2}$ and Andreas Sicklinger ${ }^{3}$ \\ 1 Politecnico di Torino, Department of Architecture and Design, 10129 Turin, Italy \\ 2 Freelance, 42120 Reggio Emilia, Italy; elisa.reinaudo@gmail.com \\ 3 Product Design Department, Faculty of Applied Sciences and Arts, Tagamo El Khames The German \\ University in Cairo, New Cairo 11835, Egypt; sicklinger.andreas@guc.edu.eg \\ * Correspondence: massimiliano.loturco@polito.it; Tel.: +39-011-090-4392 \\ + Presented at the International and Interdisciplinary Conference IMMAGINI? Image and Imagination \\ between Representation, Communication, Education and Psychology, Brixen, Italy, 27-28 November 2017. \\ Published: 14 November 2017
}

\begin{abstract}
Mental imagery is a familiar aspect of most individuals' mental lives, considered as an experience which occurs in the absence of actual stirrings for relevant perceptions. The primary importance of mental imagery has been demonstrated in several domains: learning and memory, reasoning and problem solving, inventive or creative thought and rehab. The project primarily refers to the analysis of infant visual impairment for a first scientific and social approach, with specific references to significant figures who have worked on these issues for years. Research is enriched by the contribution of educators working with children with these diseases. Thus, the proposal of a freehand illustrated tactile book, originally conceived for sighted and then reworked for blind and visually impaired, through the humanization of fantastic creatures designed to facilitate imaginative faculties, allowing the child to project his to an inanimate model.
\end{abstract}

Keywords: imagery; images; mental representations; visual impairment

The soul never thinks without a mental image

[Aristotle, De anima, 431a 15-20]

\section{Introduction}

In "Letter on the Blind for the Use of those who can see", Denis Diderot in 1749 takes on the question of visual perception in certain cases of blindness from birth. According to Diderot's essay, a blind person who is suddenly able to see for the first time does not immediately understand what he/she sees. A blind person must spend an amount of time establishing relations between his/her experience of forms and distances. Then the image(s) will be, thereafter, apparent to him/her by sight. The background of Diderot's essay presents a philosophical question, known as the problem of Molyneux. This issue had been published by John Locke had in 1689, to be discussed, later, in 1798 by Immanuel Kant in his Anthropology from a Pragmatic Point of View. When medical surgery reached the level of giving blind people eyesight, this debate has found its conclusive, empiric answer by testing involved patients. Nevertheless, it keeps the learning aspect and understanding of reality open for the ones who stay blind.

Related to blind born children, this paper wants to elaborate an experience of how important mental imagery becomes within an educational project [1]. Mental imagery is a familiar aspect of most individuals' mental lives; it can be considered an experience [2]. Whether mental images have a pictorial format or not, they have been the object of the well-known imagery-debate. In this debate, 
and for several decades, two main theoretical positions have been challenging each other: the pictorial (or depictivist) theory [3] and the propositional (or descriptivistic) theory [4].

According to Kosslyn's studies [5], mental images are formed through representational brain states that are genuinely "picture-like". Based on specific findings and tests that are not mentioned here, images in the mind were considered to be functionally equivalent to inner pictures that can be considered as a sort of copy of previous sensory impressions [6]. Maintaining information in the form of an image, where a lot of data can be simultaneously combined, is more economical than maintaining it in the form of propositional description [7]

Jean Paul Sartre [8] and Ludwig Wittgenstein [9], stated clearly that, from imagery, no new information derive, a strong contrast to perception. Thus, perception is the input or "platform" on which the mental imagery can be built. Mainly, sensorial observation and logic inferences can lead to knowledge. It has been argued that mental imagery can and does support types of inference that bring genuine and new knowledge about the real world, [10]. Nielson and Norman's study [11] on virtual interfaces can be a good example. In that study, the mental image becomes a virtual, non-real model, through which the user builds his/her interaction with an untouchable system, i.e., web pages, primarily based on previous experiences.

Furthermore, the primary importance of mental imagery has been demonstrated in several domains, such as learning and memory [12], reasoning and problem solving [13], inventive or creative thought [14] and rehabilitation, to name the main ones.

This topic is very complex and deeply structured. Therefore, the book Blind Vision treats it with extreme rigor. The authors tried to convey the idea that blindness is not "less", but "alter" [6]. They have used both visual and spatial cognition, as well as compensatory mechanism, that are activated in people with partial or complete visual impairment.

\section{The Educational Project}

As stated before, mental imagination occurs in the absence of actual stirrings by relevant perceptions. There are regions of the brain that process information even when there is no sensorial deficit. Regardless of its original sensorial sources, they respond to a specific object whether it is seen or touched [15].

The learning process is already complex; it involves abstract forms and requires the transformation into realistic and imaginative content. Thus, it is an advantage to refer to the general capacity of children to learn reading abstract letters and words. Regardless of the existing sense of view, the human brain needs to adapt and create new neurologic connections in order to read and transform a word into a real image. Wolf stated "there are no genes which are specialized in reading. In contrast to its components, such as seeing and talking, which are organized on a genetic level at the birth of the child, for reading there not direct genetic program available" [16].

This means that as any cultural invention, reading must be learned through exercise. Recent researches have shown that the capacity of learning how to read, depends highly on the time spent by parents and educators in reading stories as early as preschool age. By time, the child starts to connect stories with forms and meanings, and revive emotions, to analogue mental imagery. The latter is hardly studied by researchers in the field of educational sciences.

Thus, if these issues to be applied to an educational project, the topic would require a degree of complexity. Many variables related to the learning and development capabilities of the different areas of the brain (linguistic, mathematical logic, scientific, historical, anthropological, technical, and expressive) need to be taken into account reinforcing mental representations and cognitive experiences that determine the learning processes.

The project of this paper primarily refers to the analysis of infant visual impairment, for a first scientific and social approach, with specific references to significant personalities who have worked on these issues for years. Research is enriched by the contribution of educators working with children with these problems.

As stated before, it is necessary to deeply investigate the strong relationship between imagination and emotions. The emotional growth of children is not an appendix; it must be 
considered as an essential element of evolutionary development through narrative experiences as the children grow.

Furthermore, imagery enriches the real, as much as rationality, since it explains and orders it. Simply, it works in its own way. Logic seeks rules, links and laws that can always, and in any case, be in agreement with science, while anybody can agree with it. Imagery, however, becomes imagination and develops connections that are linked to the inner world of those who use it; so they may be true and real just for this person [17].

Defining the context of intervention is crucial for the design process. In this project, it has been achieved with the valuable contribution of Adriana Rosso, an educator and expert in orientation and autonomy at the Non-Visual Documentation Center, Turin, Italy. She was helpful for the realization of structured materials based on specific rules referring to Wibur Schramm [18] that precisely determine the structural and constructive characteristics, such as size (Figure 1), shape and texture. The aim was to stimulate a single type of response. Such products are generally used in nurseries and elementary schools [19], as they are dedicated to development phases between the pre-conception and intuitive phases [20].

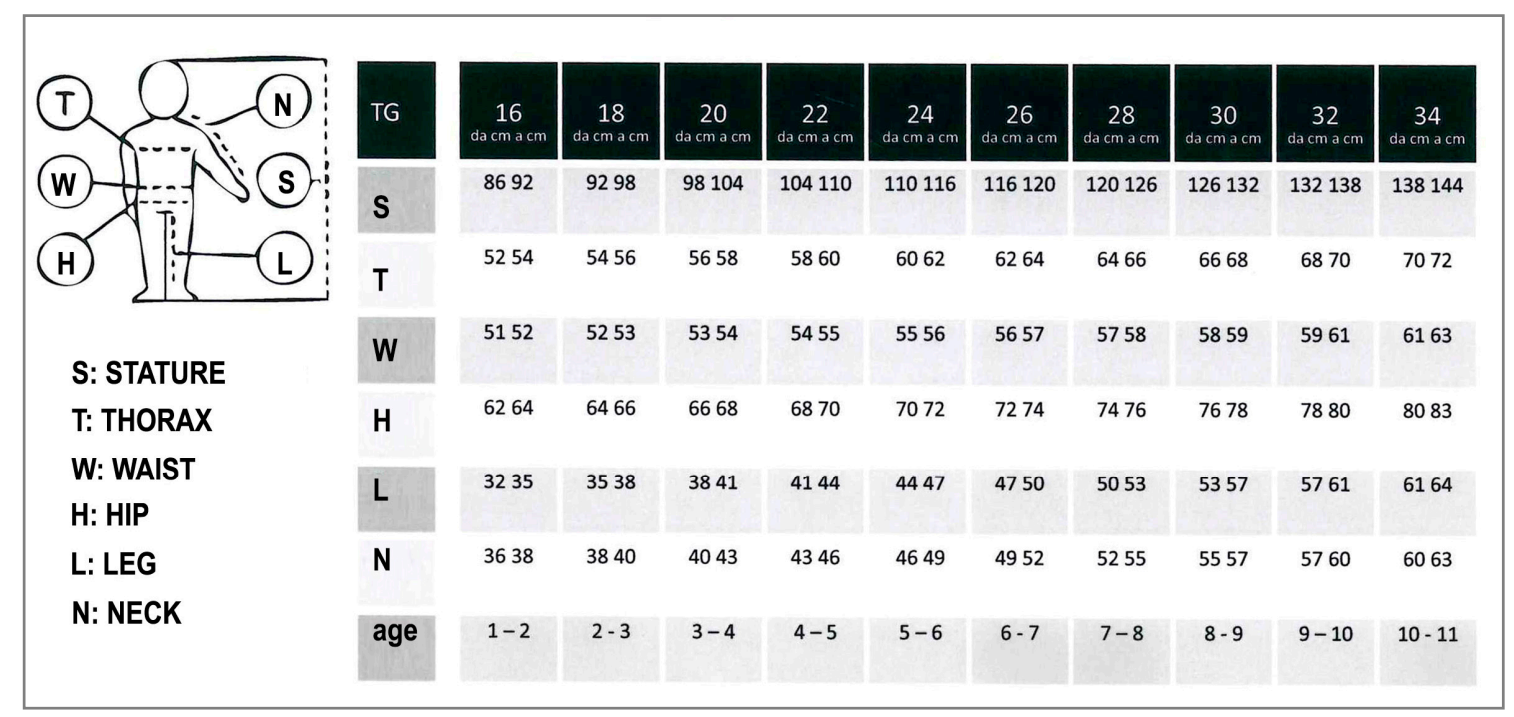

Figure 1. Synoptic schedule related to the anthropometric relationships of children as their height increases.

\section{The Case Study: Hi, I Am Lini}

Vision is the primary sensory modality in the spatial-cognition and object identification [21]. As previously stated, if vision is lost in the blind, the audition, touch and olfaction are still functioning and they represent the channel through which a blind person gets to know about the world. Touch and hearing can provide sufficient information for a blind person to generate a reliable internal representation of the external world. Thus, the proposal of a freehand-illustrated tactile book was originally conceived for sighted and then reworked for blind and visually impaired. Adaptation is done through the humanization of fantastic creatures designed to facilitate imaginative faculties, thus, allowing the child to project his/her physicality (having the nose, the mouth, the eyes, etc.) to an inanimate model. The major design rules described in the rich literature references have been respected. Moreover, these standards were implemented in various products; for instance, Braille writing tactile book, story-building cuddly toys, memory games, and puzzles specifically designed to work on tactile sensations.

In addition, child's knowledge is based on the interaction between subject and object. The subject acts on the object and manipulates it. The game, as it is known, has a remarkable social function of interaction and sharing, and consequently becomes the means to understand the development and the imaginative capacity of the child [22]. 
The proposal, therefore, extends the interaction from a two-dimensional surface with relief elements (a special printing technique between cut image and Braille) to use in other game elements that integrate and confirm the child's mental image. The presentation of the protagonist is made of a cuddly toy, while its activities can be expressed through table games, as the famous memory game. The memorization is finally reinforced with a puzzle that allows children to rebuild the character by aggregating individual moments in the storytelling.

This type of education is capable of adding a touch of curiosity and more shades. This is thanks to its collaboration of cross-channel variables, learning abilities, and advancement of cerebral areas, i.e., linguistic, logic and math, scientific, historical and anthropological, technical and expressive areas. Its closeness to growth makes its role fundamental. Thus, a communicative channel, suitable for children's imagination, can be effectively used as a growth tool.

This project is directed to the specific period of childhood that Piaget referred to as pre-conceptual and intuitive phases, from both social and scientific points of view, with many references to authoritative figures who have worked on these topics through the years. The whole work aims at providing a path, giving the children the chance to create a connection between bi-dimensional and three-dimensional elements of a story.

The scope of this project has to be cleared due to fact parameters and measurements changes, according to the requirements it involves. Each of the aspects considered follows certain guidelines to satisfy specific needs. Dimensions, shapes and textures are the vectors the child will use while experiencing the surrounding environment.

The first introductory element is a hand-illustrated book, describing the main character (see Figure 2), and his friends. The fairy tale, perhaps more than anything else, is considered a "democratic" element that would reduce the distance between the two realities, normal sighted children and the ones with visual impairments, as far as imagination and fantasy are main players. In both cases, it possible to direct the involvement into a cognitive, emotional, relational and/or bodily dimension(s), whether separately or combined. Through a proper grammar of the imaginary, it was possible to lead the reader to intelligent use of the fairy tale, transforming it from an instrument of entertainment into a tool of human growth and personal maturity. A Braille text, relating to the images, completes the amount of content provided.

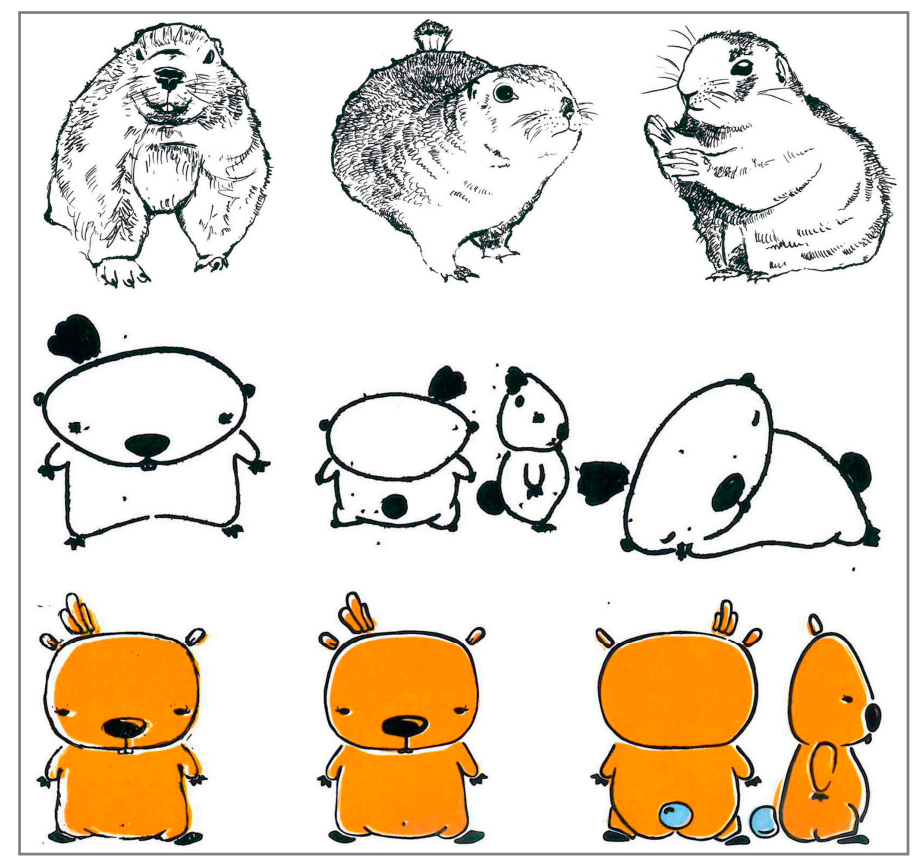

Figure 2. The choosing of the protagonist: from the left, to the right, a prairie dog, a crib and a marmot. Below, the progressive drawing of the marmot: the simplification is useful to facilitate children affected by visual impairments in the recognition of the different parts. Drawings made by E. Reinaudo [23]. 
The protagonist of the story is Lini, a groundhog living in a canary cage which floats in the air and contains fluffy pillows, a tiny table, and a couple of chairs in it. A ladder drives to the entrance and some flowers perfume this little space. Cats, flies, and many other animals animate his life, sharing interests such as music and sweets. The printing technique called 'Minolta 3D printing' makes outlines able to be sensed through touch (Figure 3).

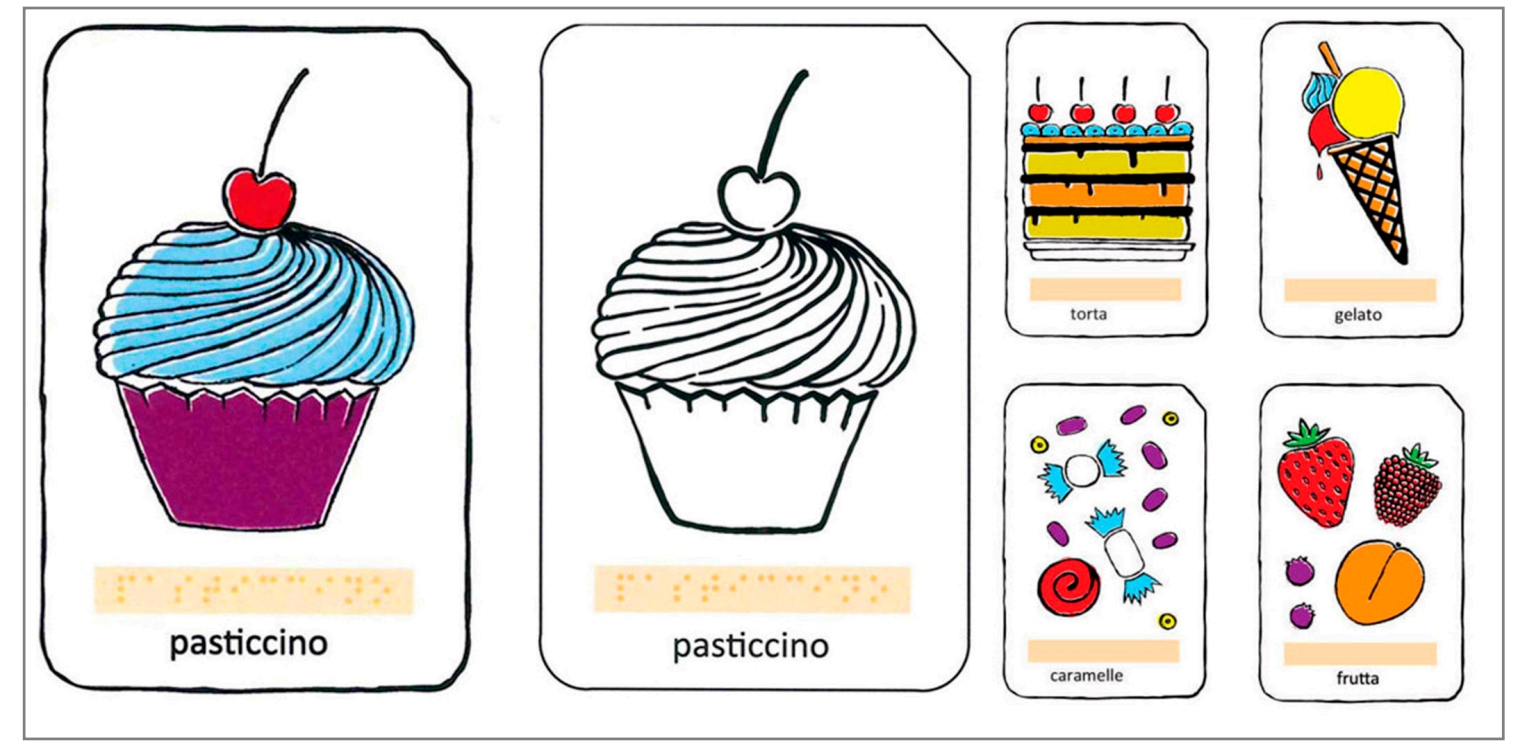

Figure 3. Some cards used for the memory game. The name of the subject is written in Braille, while the drawings have the contour lines in relief, in order to help the children to recognize the subjects. The cards have beveled edges: three of them are rounded, while the upper right corner is more linear. This is a tactile indicator that facilitates the correct reading direction of the card.

Cold transferred graphics on thermo-sensitive micro-capsules paper and then passed in a special oven, to make it possible to see the dark parts of an illustration rise. A following coloring session adjusts tone and tints for those who need contrast to aid understanding the medium (Figure 4).
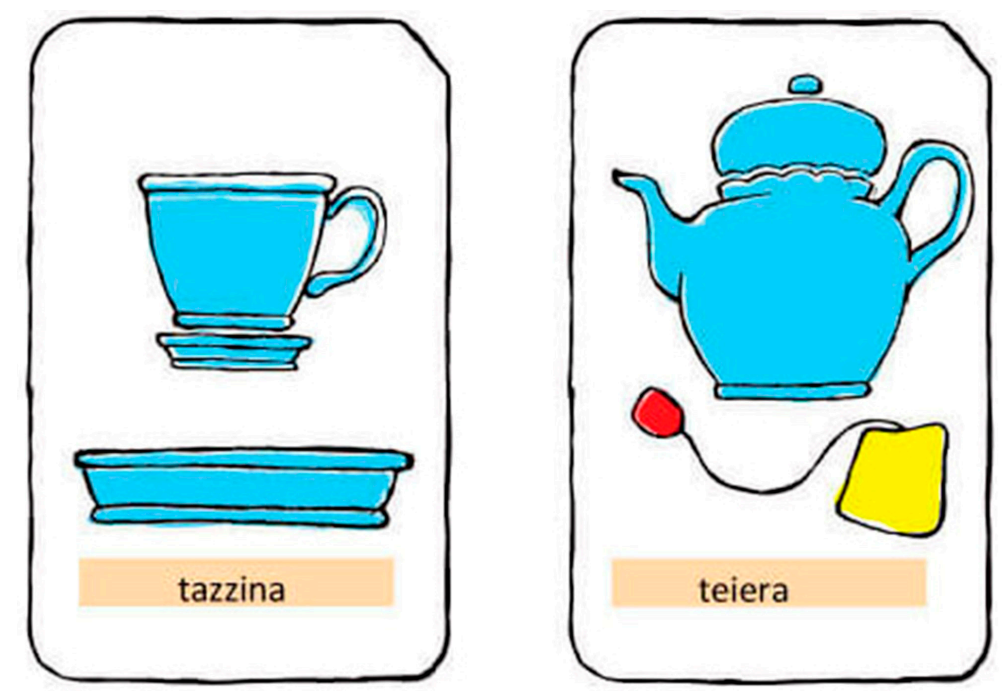

Figure 4. The playing cards depict similar and simple elements: one subject is the protagonist; the second is a subordinate and aggregate, which can be a cue of wonder, question, or necessity by stimulating the ability to relate the information. This mechanism, at the basis of fantastic elaboration, can lead into the imaginative process and, in the future, drives to creativity and invention.

The experience, then, develops into a memory game to strengthen the information collected while reading. After that comes the turn of a puzzle to see if children remember the protagonist's 
main traits, and are able to transfer them onto a larger version of the creature (Figure 5). In the end, the child is called to handle a big cuddly toy depicting Lini.

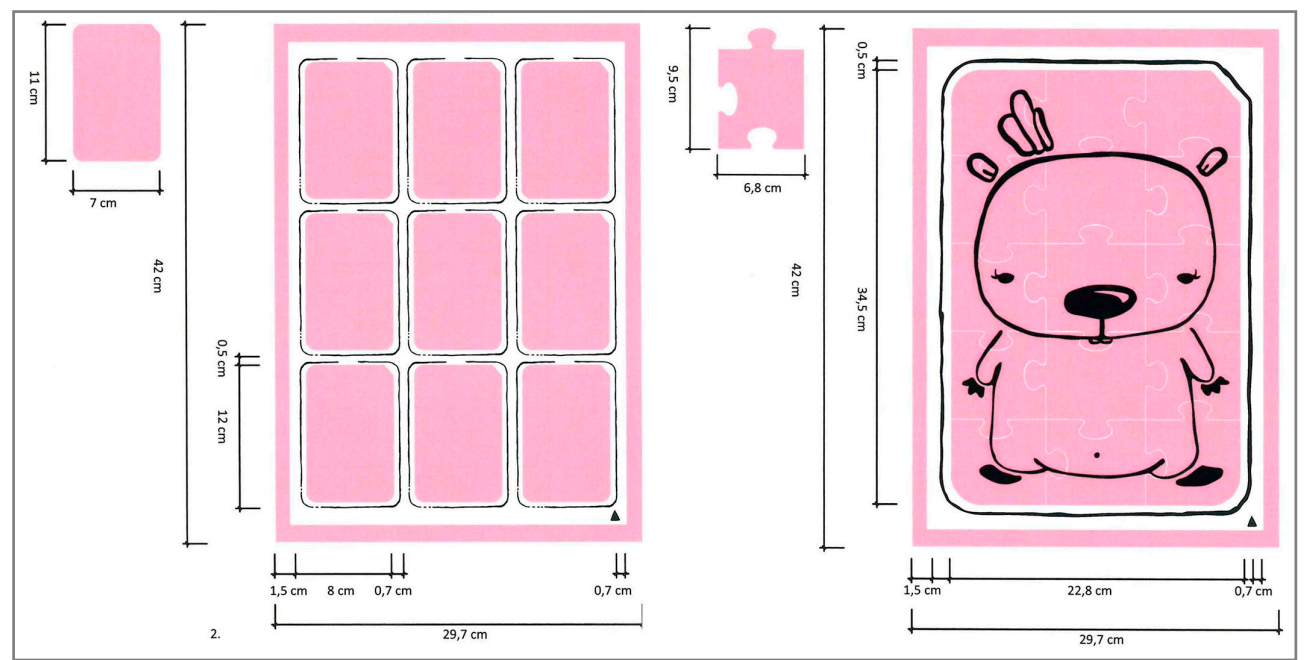

Figure 5. On the left, one of the two designs for the memory game. On the right, dimensions and complete drawing of the puzzle. The creation of a single big box allows users not to go out of the game space. The number and size of the pieces take into account the perceptible size of the touch, and the number of information that the child can store and his age.

\section{Conclusions}

Imagination is the ability to create relations between known elements, leads to the representation of virtual concepts which otherwise would lack a real representation. The use of fantastic or analogue languages is thought to stimulate the inner world, to communicate emotions, and to develop the personal creativity of children (Figure 6).

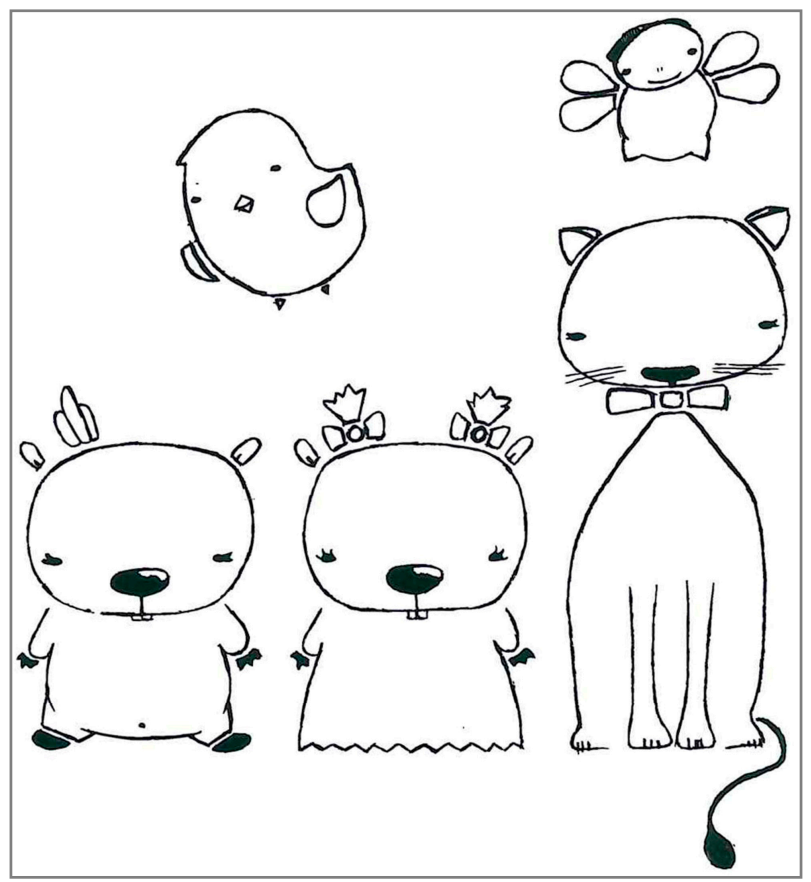

Figure 6. The protagonists of the full story: the male companion of the protagonist, a bumblebee, a cat, and a canary. All the drawings, shown born as sketches on paper, are later imported to the Adobe Illustrator application. The final version of the various subjects is reported before being sent to the printer, then heated in the oven and colored by hands. 
The fairy tale represents a rich language that helps children to enhance their inner life skills, which can help to form associations between emotional and bodily experiences. In the absence of vision, the other senses work as functional substitutes and thus are often improved (i.e., sensory compensation). Consequently, sensory compensations allow blind individuals to interact with the external world and perfume the everyday activities [24].

Imagination visualizes, capture, and creates mental pictures. Creativity comes to the surface and inventions circumscribe its contents, needs and requirements, describing its final physical declination. Haptic and auditory experiences are necessarily correlated, while vision allows parallel processing of multiple distinct input into a unique meaningful representation. This variable is the main element to be considered. The invariant aspect has been supported by the latest neuroscience studies, concerns the production of mental images, equivalent to inner picture, intended as copy of previous sensory, not only visual, impressions.

Acknowledgments: Sincerely thanks go to Elisa Reinaudo. We have had the pleasure of accompanying her during her degree thesis. Her activities, supported by the authoritative references cited in the present work, constitute the core of the whole research, constituting a very important substrate to work together, to solve the problems, and to analyze proposals for the illustrated case study. Special thanks of the valuable contribution goes to Adriana Rosso and to the Non-Visual Documentation Center, in Turin, Italy, for the helpful suggestions and the energy employed during such laborious activities.

Author Contributions: Although this work is the result of collegial considerations and elaborations by all the authors, the paragraphs are mainly edited individually as the following order: the Introduction was mainly edited by Massimiliano Lo Turco The educational project was mainly edited by Andreas Sicklinger; the case study was mainly edited by Elisa Reinaudo; the conclusion paragraph was written by all authors.

Conflicts of Interest: The authors declare no conflicts of interest.

\section{References}

1. Stanford Encyclopedia of Philosophy. Available online: https://plato.stanford.edu/entries/mental-imagery/ (accessed on 5 September 2017).

2. Rinck, M.; Denis, M. The metrics of spatial distance traversed during mental imagery. J. Exp. Psychol. Learn. Mem. Cognit. 2004, 30, 1211-1218.

3. Kosslyn, S.M. Scanning visual images. Some structural implications. Perception Psychophys. 1973, 14, 90-94.

4. Pylyshyn, Z.W. What the mind'eye tells the mind's brain: a critique of mental imagery. Psychol. Bull. 1973, 80, 1-24.

5. Kosslyn, S.M. Image and Brain: The Resolution of the Imagery Debate; The MIT Press: Cambridge, MA, USA, 1994.

6. Cattaneo, Z.; Vecchi, T. Blind Vision. The Neuroscience of Visual Impairment; The MIT Press: Cambridge, MA, USA; London, UK, 2001.

7. Thompson, W.L.; Kosslyn, S.M.; Hoffman, M.S.; Van der Kooij, K. Inspecting visual mental images: Can people see implicit properties as easily in imagery and perception? Mem. Cognit. 2008, 36, 1024-1032.

8. Sartre, J.-P. The Psychology of Imagination; Philosophical Library: New York, NY, USA, 1948.

9. Wittgenstein, L. Philosophical Investigations; Anscombe, G.E.M., Rhees, R., Eds.; Blackwell: Oxford, UK, 1953.

10. Kosslyn, S.M. Image and Mind; Harvard University Press: Cambridge MA, USA, 1980.

11. Nielsen Norman Group. 1980. Available online: https://www.nngroup.com/articles/mental-models (accessed on 5 September 2017).

12. Paivio A. Mental Representation; A Dual Coding Approach; Oxford University Press: Oxford, UK, 1986.

13. Schwartz, D.L.; Black, J.B. Analog imagery in mental model reasoning: Depictive model. Cognit. Psychol. 1996, 30, 154-219.

14. LeBoutilllier, N.; Marks, D.F. Mental imagery and creativity: A meta-analytic review study. Br. J Psychol. 2003, 94, 29-44. 
15. Pietrini, P.; Furey, M.L.; Ricciardi, E.; Gobbini, M.I.; Wu, W.H.C.; Cohen, L.; Guazzelli, M.; Haxby, J.V. Beyond sensory images: object-based representation in the human ventral pathway. Proc. Natl. Acad. Sci. USA 2004, 101, 5658-5663.

16. Wolf, M. Proust and the Squid: The Story and Science of the Reading Brain; Harper Perennial: New York, NY, USA, 2008.

17. Aldi, G. Educare Con le Fiabe. Come Sviluppare L'intelligenza Emotiva Dei Bambini; Edizioni Enea: Milano, Italy, 2014.

18. Schramm W. The Science of Human Communication; Basic Books: New York, NY, USA, 1963.

19. Sacchetti, M. Vedere Con le Mani; Edizioni Clandestine: Marina di Massa, Italy 2005.

20. Piaget J. L'epistemologia Genetica; Laterza: Bari, Italy, 1971.

21. Elmer, M. Multisensory integration: How visual experience shapes spatial perception. Curr. Biol. 2004, 14, R115-R117.

22. Sicklinger, A. (Ed.) Design e Ipovisione, Dalla Leggibilita' al Design Multisensoriale; Maggioli Editore: Santarcangelo di Romagna, Italy, 2009.

23. Reinaudo, E. Con_Tatto: Dall'analisi al Progetto in Ambito di Disabilità Visiva Nel Periodo Dell'infanzia; Bachelor Degree in Graphic and Virtual Design; (Tutors: Sicklinger, A., Lo Turco, M., Rosso, A., Fellini, M.); Politecnico di Torino: Turin, Italy, 2011.

24. Sunderland, M. Aiutare i Bambini...A Esprimere Emozioni: Attività Psicoeducative Con il Supporto di Una Favola; Erickson: Trento, Itably, 2011.

(C) 2017 by the authors. Licensee MDPI, Basel, Switzerland. This article is an open access article distributed under the terms and conditions of the Creative Commons Attribution (CC BY) license (http://creativecommons.org/licenses/by/4.0/). 